\title{
PATRONES ESPACIO TEMPORALES DE LA CONDICIÓN MICROBIOLÓGICA DEL AGUA DE FUENTES COMUNITARIAS Y AMENAZAS A LA SALUD FAMILIAR EN CUENCAS ESTACIONALES DEL BAJO BALSAS (MÉXICO)
}

\author{
Ana Laura BURGOS ${ }^{1 *}$, Margarita ALVARADO BAUTISTA ${ }^{1}$, Rosaura PÁEZ BISTRAIN ${ }^{1}$ y \\ Rubén HERNÁNDEZ MORALES ${ }^{2}$
}

${ }^{1}$ Centro de Investigaciones en Geografía Ambiental, Universidad Nacional Autónoma de México. Antigüa Carretera a Pátzcuaro \# 8701, Colonia Ex-Hacienda de San José de la Huerta, Morelia, Michoacán, México, C. P. 58190

${ }^{2}$ Laboratorio de Biología Acuática, Facultad de Biología, Universidad Michoacana de San Nicolás de Hidalgo. Edificio R, Planta Baja, Francisco J. Múgica, Ciudad Universitaria, Morelia, Michoacán, México, C. P. 58040

*Autor para correspondencia: aburgos@ciga.unam.mx

(Recibido marzo 2016; aceptado agosto 2016)

Palabras clave: calidad microbiológica del agua, seguridad hídrica, enfermedades relacionadas con el agua, trópico seco, cuenca del Río Balsas

\section{RESUMEN}

La baja calidad microbiológica del agua rural es un problema extendido en los países en desarrollo; en México su magnitud es incierta. Se determinaron las variaciones espaciales y estacionales de la condición microbiológica del agua en fuentes rurales de un sistema hidrográfico tropical seco y se caracterizó el manejo doméstico del agua para valorar las amenazas a la salud familiar. Durante dos años se analizaron veintidós fuentes de agua en dieciocho localidades en dos momentos contrastantes del año, al final de los periodos seco y lluvioso. La condición microbiológica de las fuentes resultó deficiente por la presencia de 35 especies coliformes termotolerantes; diez fueron coliformes de alta importancia patogénica (CAIP). La contaminación fue más severa en el periodo lluvioso por el incremento significativo en la riqueza de CAIP y en el número de sitios afectados a diferentes altitudes y órdenes de corriente dentro de las cuencas. El $49 \%$ de las familias rurales $(n=203)$ indicó el uso de técnicas domésticas de desinfección lo cual resultó asociado con el acceso a información. El 45 \% declaró padecer anualmente enfermedades transmitidas por el agua (diarreas, dolor abdominal, fiebre y vómitos), aunque el $72 \%$ de los casos que acuden a los servicios médicos quedaron sin diagnóstico clínico. La mayor contaminación por CAIP en el periodo lluvioso responde al transporte y lixiviación de desechos fecales acumulados en el periodo seco en áreas ribereñas, provenientes del ganado, fauna silvestre y población humana sin servicios sanitarios. El difícil control de la contaminación difusa resalta la importancia de incrementar la información y seguimiento a la población campesina vulnerable como parte de estrategias de seguridad hídrica en las cuencas rurales estacionales.

Key words: microbiological water quality, water security, water-related diseases, rural watersheds, Balsas River basin 


\begin{abstract}
The poor microbiological quality of rural water is a problem in developing countries; in Mexico, its magnitude is uncertain. Spatial and seasonal variations of the microbiological condition of water sources in a dry tropical hydrographic system were determined, and the domestic water management was characterized to assess threats to family health. Twenty-two sources in eighteen localities, in dry and rainy seasons, were analyzed during two years. The microbiological condition of the sources was deficient by the presence of 35 species of thermotolerant coliforms, ten of them with high pathogenic importance (HPI). The pollution was most severe during rainy season due to the significant increase in the richness of HPI species and the number of sites affected at different altitudes and order flow within the watersheds. The use of water disinfection techniques was registered in $49 \%$ of the surveyed families, who pointed out also have received information about the topic. The $45 \%$ of interviewed declared suffering from diseases transmitted by water (diarrhea, abdominal pain, fever and vomiting) annually, although $72 \%$ of the cases exposed to medical services had not been diagnosed. The highest contamination by HPI in rainfall season responds to the transportation and leaching of fecal material accumulated along dry season in riparian areas coming from livestock, wildlife and human population without sanitation services. The difficult control of diffuse pollution highlights the importance of increasing the information and monitoring of the household water management by rural vulnerable population as part of strategies for water security in seasonal rural watersheds.
\end{abstract}

\section{INTRODUCCIÓN}

La baja calidad microbiológica del agua en fuentes de abasto en áreas rurales es un problema extendido en los países en desarrollo (Nogueira et al. 2003, Trevett et al. 2004, Mpenyana-Monyatsi et al. 2012, Jagals et al. 2013, Amenu et al. 2014). La evaluación de esta problemática bajo diferentes contextos geográficos contribuye al entendimiento de los factores implicados en la seguridad hídrica rural a escala global (Fewtrell y Bartram 2001, WHO 2011). Asimismo, es prescriptiva de las medidas preventivas, correctivas y de manejo para reducir las causas y efectos del problema en territorios y cuencas específicas (Valenzuela et al. 2009).

La calidad microbiológica del agua es medida por la presencia de bacterias coliformes termotolerantes capaces de fermentar lactosa a temperaturas de 44-45 ${ }^{\circ} \mathrm{C}$, las que están asociadas a la presencia de material fecal. Escherichia coli y el género Salmonella son los principales indicadores de contaminación fecal, con efectos patogénicos severos para el ser humano. Otras especies de interés patogénico son Vibrio colera, especies del género Escherichia y algunas de los géneros Campylobacter, Enterobacter y Yersinia (Bain et al. 2014a). Otros géneros como Edwarsiella tienen efectos moderados o nulos en la salud humana, aunque pueden afectar la sanidad de especies agrícolas y silvestres (Crumlish et al. 2002).

En las áreas rurales marginadas, la baja calidad microbiológica del agua se conjunta con la alta vulnerabilidad de la población. Las familias campesinas cuentan con baja escolaridad, falta de acceso a la información, grupos etarios extremos, aislamiento geográfico, falta de servicios de salud y abandono gubernamental (Akoachere 2013, Bain et al. 2014b). Estos rezagos favorecen el manejo deficiente del agua al interior de la vivienda lo que está asociado a un mayor deterioro de su calidad e incremento de riesgos a la salud familiar (Günter y Schipper 2013, Rosa et al. 2014).

Si bien México es un país de ingresos medios-altos (OCDE 2015), sus áreas rurales sufren rezagos similares a los de los países menos favorecidos. Una gran parte del México rural se encuentra bajo condiciones climáticas estacionales donde la pobreza se agudiza por la presencia de largos periodos estivales con una marcada escasez de agua para atender las necesidades básicas. México reportó un avance significativo en el abasto de agua a poblados rurales para atender los Objetivos del Milenio (SIODM 2015). Sin embargo, queda aún por indagar la magnitud de la problemática asociada a la calidad microbiológica de las fuentes comunitarias de agua. Con el propósito de contribuir al alcance de la seguridad hídrica en el México rural, este trabajo persiguió dos objetivos. El primero fue determinar los patrones espacio temporales en la condición microbiológica del agua de fuentes de abasto comunitario en cuencas rurales de alta marginación social, afectadas por climas estacionales secos. El segundo fue identificar las amenazas sobre la salud 
comunitaria asociadas al manejo intradomiciliario del agua en la población campesina que habita dichas cuencas.

\section{MATERIALES Y MÉTODOS}

\section{Área de estudio}

El estudio se realizó en un sistema hidrográfico de $1300 \mathrm{~km}^{2}$ que drena al embalse Adolfo López Mateos (Presa Infiernillo) en la parte baja de la cuenca del Río Balsas en la región de Tierra Caliente, Michoacán, México (Fig. 1). La cuenca del Balsas está dominada por dos tipos climáticos: cálido subhúmedo $A_{w_{0}} \mathrm{y}$ semiárido cálido $\mathrm{BS}_{1}$ (Trejo 1999). La precipitación anual promedio es de $650 \mathrm{~mm}$ si bien el $90 \%$ precipita entre junio y octubre con un periodo seco que dura de 6 a 7 meses. El área es representativa del trópico seco del Pacífico mexicano y está caracterizado por la presencia de selvas bajas, un ecosistema nativo con interesantes y únicas adaptaciones a la sequía (Ceballos et al. 2010). Los pobladores radican en pequeñas localidades dispersas en un paisaje dominado por cerros y lomeríos, las cuales muestran rezagos sociales y económicos que las clasifican como de alta y muy alta marginación (CONAPO 2012). El agua doméstica es obtenida de pequeños escurrideros de las partes altas de cerros y manantiales permanentes o desde acuíferos aluviales someros en los cauces de arroyos transitorios. El aprovechamiento se realiza con infraestructura hídrica precaria. En sitios altos, se utilizan cajas de captación para conducir el agua por gravedad a los poblados; en las partes bajas, el agua se extrae de acuíferos aluviales mediante norias y equipos de bombeo. En ambos casos, el agua es conducida primero a los depósitos comunitarios y luego, mediante una red de distribución, a las viviendas. Los depósitos carecen de tratamiento de agua aunque en ocasiones existen casetas para la colocación de clorinadores que nunca han entrado en uso. En el periodo seco, cuando el agua es insuficiente, las familias buscan fuentes alternativas como pequeños manantiales o realizan excavaciones en los cauces secos de los arroyos.

\section{Hipótesis de trabajo}

La investigación se orientó por las siguientes hipótesis de trabajo:

$\left[\mathrm{H}_{1}\right]$ Por ser una región rural, las fuentes comunitarias de agua para uso doméstico mostrarán contaminación microbiológica similar a la reportada para áreas rurales de países en desarrollo, con presencia y amplia distribución de las bacterias Escherichia coli y Salmonella sp.

$\left[\mathrm{H}_{2}\right]$ El carácterestacional del clima promoveráunamayor severidad de la contaminación microbiológica

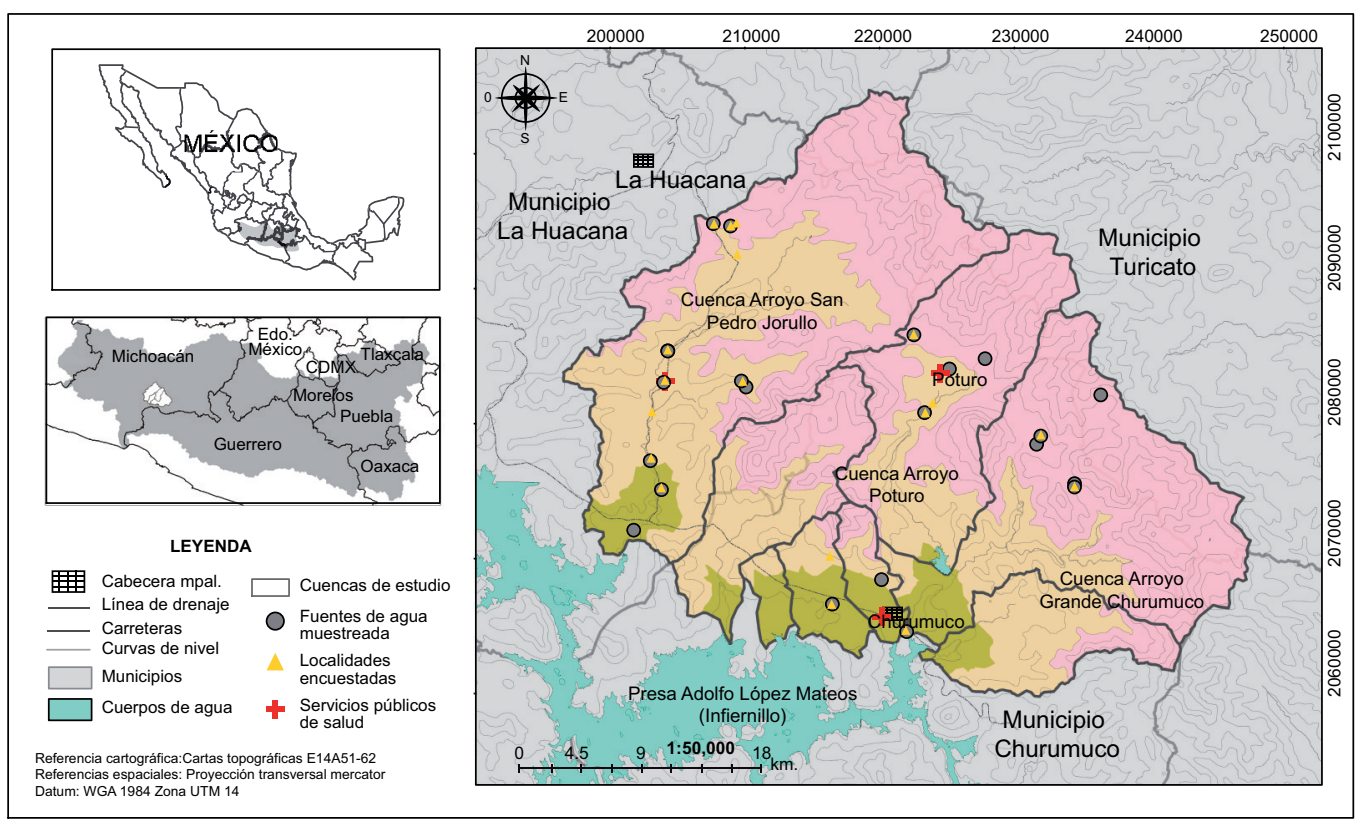

Fig. 1. Ubicación de la cuenca del Río Balsas (izquierda) y del sistema hidrográfico Presa Infiernillo-Bajo Balsas en el Estado de Michoacán, con los sitios de muestreo de fuentes de agua ( $\mathrm{n}=22$; círculos grises) y de aplicación de encuestas ( $\mathrm{n}=18$; triángulos oscuros) 
a finales del periodo seco (mayo), observado en la distribución más amplia de especies entre los sitios de aprovechamiento del sistema hidrográfico, y una mayor riqueza de especies de alta importancia patogénica en cada sitio.

$\left[\mathrm{H}_{3}\right]$ En el sistema hidrográfico, la distribución espacial de la contaminación bacteriológica será más grave en los sitios de aprovechamiento ubicados en líneas de drenaje de mayor orden de corriente (partes bajas).

$\left[\mathrm{H}_{4}\right]$ Dada la alta vulnerabilidad social, la adopción de prácticas intradomiciliarias de desinfección será altamente deficiente, lo que se reflejará en una muy alta incidencia de enfermedades transmitidas por el agua en el seno del grupo familiar.

\section{Diseño del muestreo de fuentes de agua}

El muestreo se realizó en 22 sitios de aprovechamiento de fuentes de agua para uso comunitario, ubicados en 18 localidades del área de estudio (Fig. 1). Los sitios se seleccionaron de entre 42 fuentes de agua cuyos parámetros fisicos y químicos son analizados desde el año 2010 mediante un programa de monitoreo comunitario de calidad del agua (Burgos et al. 2013). Se escogieron localidades y sitios distribuidos en todo el sistema hidrográfico para cubrir condiciones a diferentes altitudes y sobre líneas de drenaje de diferente orden de corriente (Cuadro I). El muestreo se realizó durante los años 2014 y 2015 a finales del periodo seco ( 24 de mayo y 8 de junio, respectivamente) y lluvioso (19 y 11 de octubre). Los meses de mayo y octubre muestran condiciones contrastantes y son momentos de alta estabilidad hidrológica en estas cuencas estacionales. Las muestras de agua se colectaron por duplicado en bolsas estériles de $100 \mathrm{~mL}$ y se mantuvieron en hielo hasta su colocación en refrigeración a $4{ }^{\circ} \mathrm{C}$ a la noche del mismo día de colecta. Los análisis de laboratorio se iniciaron a primera hora del día siguiente.

\section{Procedimientos de laboratorio}

Los análisis microbiológicos se realizaron mediante pruebas presuntivas y confirmativas para determinar el número más probable (NMP) de bacterias coliformes totales y fecales, de acuerdo con la técnica prescrita por NMX-AA-042-SCFI-2011 (SCFI 2013). Se utilizaron los medios selectivos para organismos de la familia Enterobacteriaceae como agar MacConkey y eosina azul de metileno (Brooks et al. 2011). La identificación taxonómica se realizó con el manual de bacteriología sistemática de Bergey (Holt et al. 1994) con el que se discernió entre grupo taxonómico, género y especie, con base en 14 características fenotípicas de tipo bioquímico: tinción de Gram (24h), oxidasa (24h), producción de indol, rojo de metilo, Voges-Proskauer $\left(25-28\right.$ y $\left.37^{\circ} \mathrm{C}\right)$, citrato de Simmons $\left(25-28\right.$ y $\left.37^{\circ} \mathrm{C}\right)$, producción de ácido sulfhídrico, hidrolisis de urea, desaminasa de fenilalanina (24h), descarboxilasa de lisina, motilidad $\left(25-28\right.$ y $\left.37^{\circ} \mathrm{C}\right)$, hidrólisis de sustrato, fermentación de azúcares y producción de gas (Fung 2014, Sandle 2014).

\section{Análisis de datos microbiológicos}

Las especies confirmadas fueron clasificadas por su importancia patogénica para el ser humano bajo criterios derivados de bibliografía médica especializada (Cuadro II). La presencia temporal de cada especie fue categorizada como 'persistente' cuando la especie fue detectada en las cuatro fechas al menos en uno de los sitios de muestreo; 'cuasi-permanente' si fue detectada en tres fechas; 'estacional' o 'errática', con presencia en dos fechas del mismo o diferente periodo (seco o lluvioso) y 'eventual' cuando la especie fue detectada solamente en una fecha.

La severidad de la contaminación microbiológica fue establecida mediante la riqueza de especies de bacterias coliformes termoestables (CT) y la riqueza del subgrupo de coliformes de alta importancia patogénica (CAIP), para cada sitio de aprovechamiento y fecha de muestreo. Los datos de CT y CAIP no siguieron una distribución normal por lo que se utilizaron pruebas de estadística no paramétrica. Para probar los efectos de la estacionalidad climática (periodo seco vs. lluvioso) se aplicó la prueba de comparaciones pareadas de Wilcoxon, tanto sobre la distribución espacial de cada especie (contraste de $\left[\mathrm{H}_{1}\right]$; especie $\mathrm{X}$ número de sitios); como para comparar la severidad de la contaminación en un mismo sitio de aprovechamiento (contraste de [H2]; sitio X número de especie). Para probar $\left[\mathrm{H}_{3}\right]$ se utilizó la prueba de Kruskal-Wallis aplicada a los datos de riqueza de CAIP en los sitios de aprovechamiento de agua agrupados de acuerdo al orden de corriente de la línea de drenaje donde están ubicados (Cuadro I). Los análisis fueron realizados con el programa Statistica V. 10.0.

\section{Manejo intradomiciliario del agua y salud familiar}

Para contrastar $\left[\mathrm{H}_{4}\right]$ se aplicó una encuesta estructurada organizada en dos bloques de preguntas, que fue dirigida a las mujeres a cargo del hogar. El primer bloque indagó sobre temas como la información recibida sobre la calidad microbiológica y las enfermedades transmitidas por el agua (ETA), las fuentes de abasto de agua de la vivienda, los tratamientos caseros de desinfección y el almacenamiento domiciliario de agua. El segundo bloque 


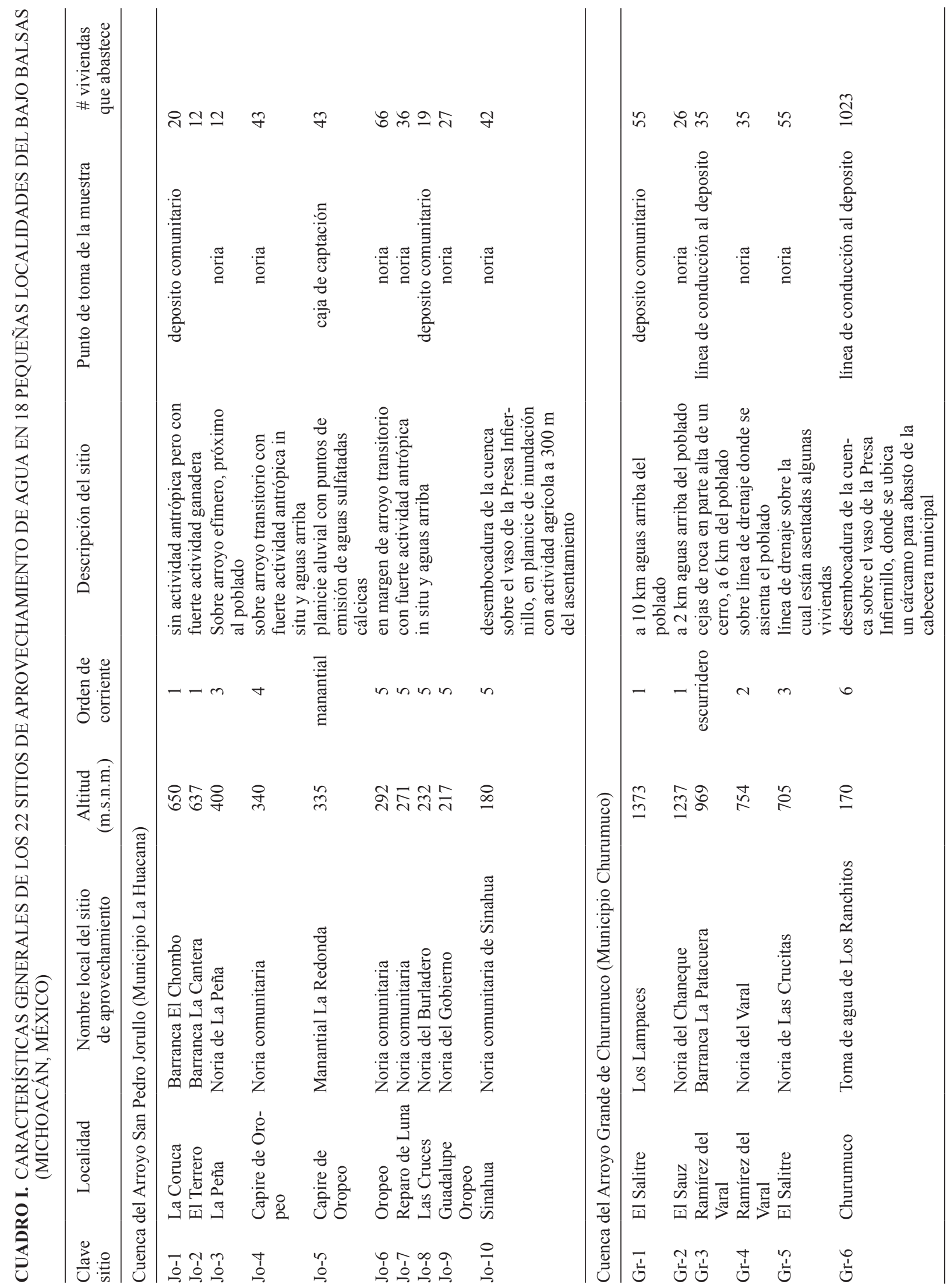


A.L. Burgos et al.

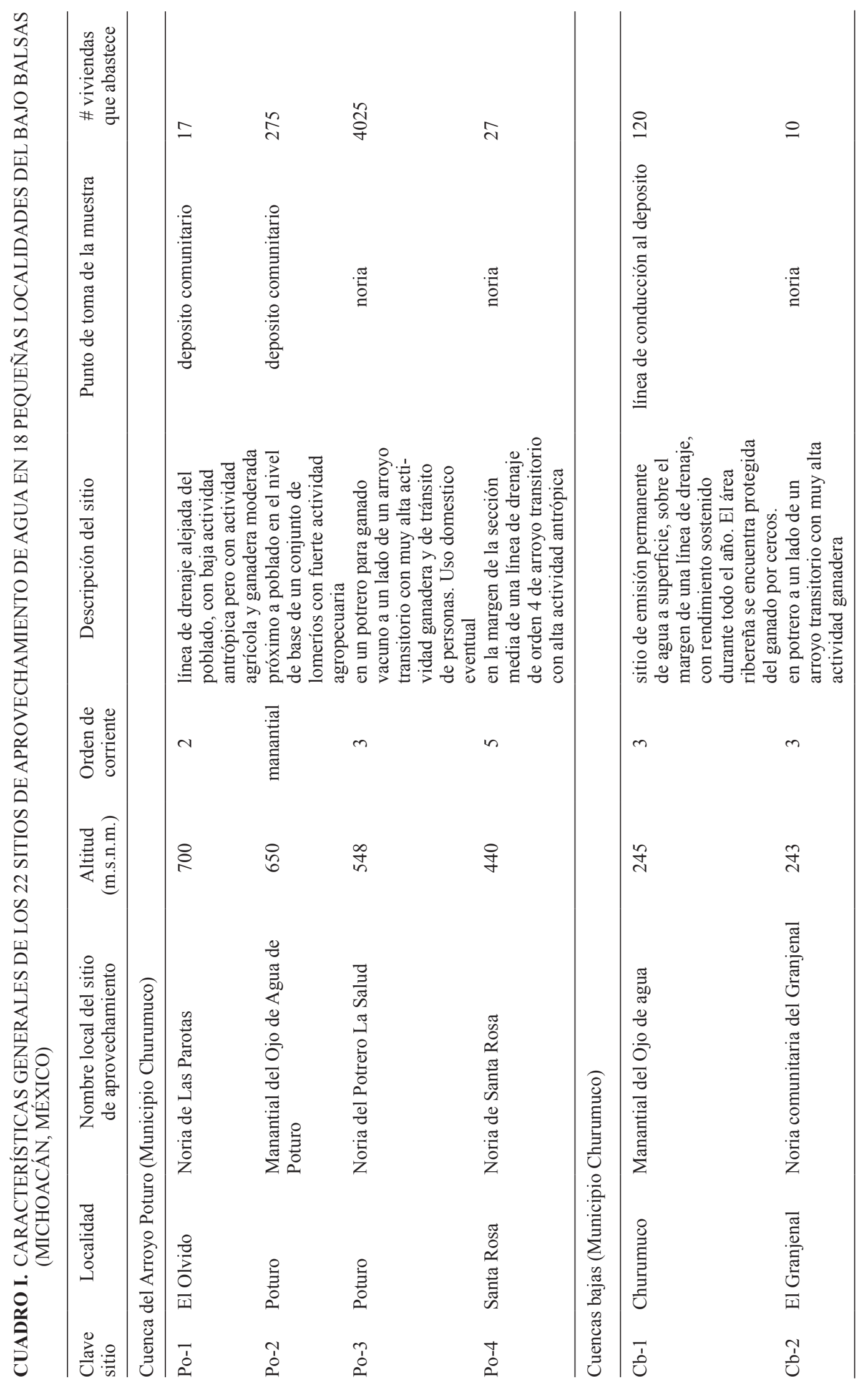


CUADRO II. CRITERIOS PARA ESTABLECER LA IMPORTANCIA PATOGÉNICA EN SERES HUMANOS DE LAS ESPECIES DE BACTERIAS COLIFORMES TERMOTOLERANTES

\begin{tabular}{|c|c|c|}
\hline Categoría & Criterio & Ejemplo \\
\hline Muy alta & $\begin{array}{l}\text { Muy amplia distribución en el ambiente (agua, suelo, aire) y en el intestino de } \\
\text { animales y humanos. Son agente causal de enfermedades gastrointestinales y } \\
\text { extra-intestinales (urinarias, respiratorias, bacteremia) en personas sanas y en } \\
\text { brotes nosocomiales. La principal vía de transmisión es por agua o alimentos } \\
\text { contaminados }\end{array}$ & $\begin{array}{l}\text { Escherichia coli, Salmonella sp., } \\
\text { Klebsiella pneumoniae, } \\
\text { Citrobacter diversus, }\end{array}$ \\
\hline Alta & $\begin{array}{l}\text { Amplia distribución en el ambiente y en el intestino de animales y humanos. } \\
\text { Relacionadas con gastroenteritis e infecciones importantes como endocarditis, } \\
\text { urinarias y bacteremia }\end{array}$ & $\begin{array}{l}\text { Enterobacter aerogenes, } \\
\text { Escherichia vulneris }\end{array}$ \\
\hline Moderada & $\begin{array}{l}\text { Amplia distribución en el ambiente y en el intestino de animales y humanos. } \\
\text { Patógenos oportunistas, agentes causales en brotes nosocomiales principalmente } \\
\text { y en personas con otras enfermedades como VIH, diabetes, etc. }\end{array}$ & $\begin{array}{l}\text { Edwardsiella tarda, Morganella } \\
\text { morganii, Providencia stuartii }\end{array}$ \\
\hline Baja & $\begin{array}{l}\text { Amplia distribución en el ambiente y en el intestino de animales y humanos. } \\
\text { Patógenos oportunistas con pocos reportes infecciosos. }\end{array}$ & Buttiauxella agrestis, Hafnia alvei \\
\hline Muy baja & $\begin{array}{l}\text { Amplia distribución, en agua dulce y agua potable, también en suelo. Se las } \\
\text { han aislado en excretas de personas enfermas, pero no se han identificado como } \\
\text { patógenos principales de alguna infección. }\end{array}$ & Pragia fontium \\
\hline Nula & $\begin{array}{l}\text { Amplia distribución en el ambiente, pero no se han relacionado con ninguna } \\
\text { enfermedad en humanos. Algunas son de importancia fitosanitaria y para la } \\
\text { acuacultura. }\end{array}$ & Erwinia tracheiphila, \\
\hline
\end{tabular}

recabó la incidencia de malestares asociados a ETA en la familia, su recurrencia, incidencia etaria y formas de atención. El cuestionario fue aplicado en 203 viviendas de 18 localidades entre las que se incluyeron aquellas donde las fuentes de agua fueron analizadas (Fig. 1). El 84.2\% de las encuestas fue contestada por mujeres a cargo del hogar, siendo hombres o jóvenes los informantes restantes. Del total de encuestados, el $20.2 \%$ manifestó ser analfabeta; de las personas que indicaron saber leer y escribir, el 55.3\% reportó una escolaridad de nivel primario (completa o incompleta). Los datos fueron analizados mediante tablas de contingencia (doble entrada) para identificar asociaciones bivariadas entre variables de interés como el acceso a información, la aplicación de desinfección casera, la procedencia del agua familiar y la ocurrencia de ETA.

\section{RESULTADOS}

\section{Condición microbiológica de fuentes comunitarias de agua}

Las fuentes que abastecen de agua a las comunidades rurales del sistema hidrográfico Presa InfiernilloBajo Balsas tuvieron presencia de bacterias coliformes termoestables (CT) ampliamente distribuida en el tiempo y en el espacio. La severidad de dicha contaminación fue contrastante entre los periodos seco y 1luvioso. E1 $100 \%$ de los sitios muestreados $(\mathrm{n}=22)$ tuvo presencia de CT a finales del periodo lluvioso en ambos años (2014 y 2015), mientras que la mejor condición se presentó a finales del periodo seco de 2014, con un $76 \%$ de sitios afectados. Lo más frecuente fue la presencia de más de seis especies de CT por sitio analizado al final del periodo lluvioso, con más del $50 \%$ de sitios en dicha condición (Fig. 2).

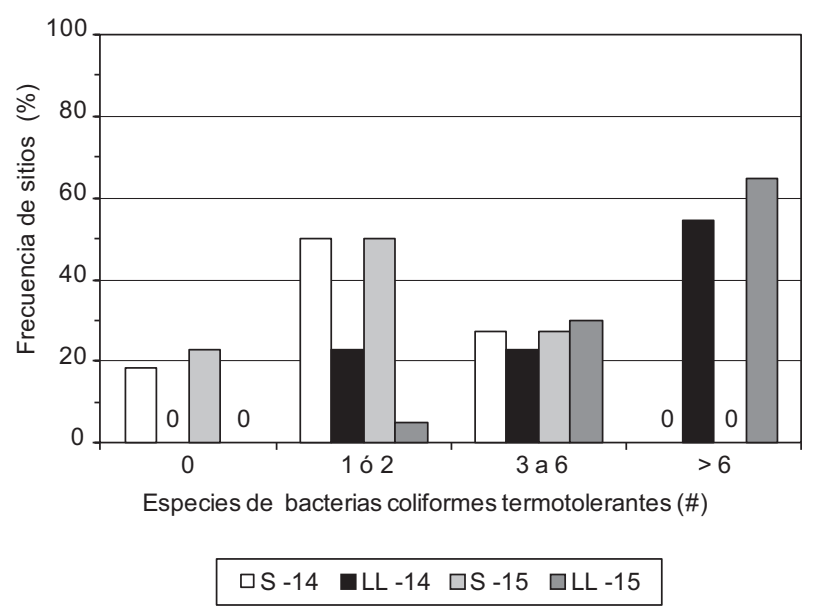

Fig. 2. Frecuencia relativa (\%) de sitios de muestreo afectados por especies de bacterias coliformes termotolerantes a final del periodo seco (S) y lluvioso (LL) en los años 2014 y 2015 
La condición menos frecuente fue la ausencia de CT en alrededor del $20 \%$ de los sitios muestreados al final del periodo seco.

Se confirmó la presencia de 35 especies de la familia Enterobacteriaceae, pertenecientes a 17 géneros (Cuadro III). Diez especies fueron clasificadas como de importancia patogénica alta y muy alta (CAIP) pertenecientes a seis géneros: Escherichia, Salmonella, Klebsiella, Yersinia, Providencia y Citrobacter. De las diez especies, seis mostraron presencia 'permanente' y 'cuasipermanente' a lo largo del periodo de muestreo, y las cuatro restantes tuvieron presencia 'estacional'. E. coli mostró una amplia distribución espacial y temporal, con presencia en más del $72 \%$ de los sitios de manera permanente. Las especies E. vulneris y Salmonella sp. mostraron una distribución espacial más restringida pero de manera permanente a lo largo del estudio. P. alcalifaciencis, K. pneumoniae subsp. pneumoniae y $Y$. pestis estuvieron presentes de manera 'cuasi-permanente' durante el estudio, con manifestación más restringida en alrededor del $15 \%$ de las sitios. De las especies con presencia estacional, destacó Enterobacter aerogenes por su aparición en lluvias en más del $20 \%$ de las fuentes y Citrobacter diversus con una menor distribución espacial pero con un muy alto impacto patogénico (Cuadro III). El inventario de CT incluyó nueve especies de importancia patogénica moderada de las cuales destacaron E. fergusonii y Edwardsiella tarda con presencia cuasi-permanente en más del $50 \%$ de los sitios. Otras 16 especies detectadas no representan amenaza sanitaria para el ser humano, pero algunas sí lo son para especies silvestres y cultivadas como Edwarsiella ictaluri y Erwinia tracheiphila que producen patologías en peces y calabaza, respectivamente (Cuadro III).

La dispersión de CT entre los sitios de aprovechamiento de agua dentro del sistema hidrográfico mostró diferencias altamente significativas entre los periodos seco y lluvioso en ambos años de muestreo $\left(\mathrm{Z}_{\mathrm{CT}-2014}=3.5870, \mathrm{p}=0.0003 ; \mathrm{Z}_{\mathrm{CT}-2015}=4.1972\right.$, $\mathrm{p}=0.0001)$. La severidad de la contaminación mostró un importante incremento en el periodo lluvioso y no en el seco, contrario a lo esperado en $\left[\mathrm{H}_{2}\right]$, expresado en una mayor dispersión espacial de especies entre sitios de aprovechamiento. El mismo patrón se detectó al realizar la prueba de Wilcoxon solamente para las especies CAIP $\left(\mathrm{Z}_{\mathrm{CAIP}-2014}=2.8031\right.$, $\left.\mathrm{p}=0.0051 ; \mathrm{Z}_{\mathrm{CF}-2015}=2.6656, \mathrm{p}=0.0077\right)$. Ello indicó que todo el grupo bacteriano, y no solamente las especies sin importancia sanitaria se diseminan en el periodo lluvioso. La prueba de Wilcoxon no detectó diferencias estadísticamente significativas en la dispersión espacial de cada especie en un mismo periodo climático entre diferentes años $\left(Z_{\text {secas }}=1.8257\right.$, $\left.\mathrm{p}=0.068 ; \mathrm{Z}_{\text {lluvias }}=1.6803, \mathrm{p}=0.093\right)$. Este resultado da certidumbre de la existencia de un patrón temporal en la dispersión de estas especies.

Además de la mayor dispersión espacial evidente en el aumento de sitios contaminados, se comprobó el incremento en la riqueza de especies tanto de CT como del subgrupo de CAIP durante el periodo lluvioso, con diferencias altamente significativas en la prueba de Wilcoxon (Cuadro IV). Contrario a lo esperado en $\left[\mathrm{H}_{3}\right]$, el incremento en la severidad de la contaminación no mostró un patrón espacial regido por el orden de corriente de las líneas de drenaje donde se ubican los sitios de aprovechamiento. Los datos indican que el enriquecimiento de CT y CAIP en fuentes de agua es un fenómeno extendido dentro de todo el sistema hidrográfico. La figura 3 muestra que, de 22 sitios estudiados, 15 manifestaron incremento en la riqueza de CAIP en el periodo lluvioso en ambos años (2014 y 2015), seis sitios lo manifestaron sólo en una ocasión y un único sitio no presentó cambios entre periodos.

\section{Manejo intradomiciliario del agua y salud familiar}

El $53.7 \%$ de las 203 personas encuestadas manifestó no haber recibido información sobre el tema de la calidad microbiológica del agua y sus efectos en la salud familiar (Fig. 4a). Solamente 101 familias (49.2\%) exteriorizó el uso de algún tratamiento de desinfección del agua de consumo. La tabla de contingencia mostró una asociación positiva y consistente entre el acceso a la información y la adopción de prácticas de desinfección casera del agua en esta población. La cloración fue la principal práctica $(74.5 \%)$, con menor uso de plata coloidal de marca comercial (20.6\%); el hervido del agua fue poco mencionado.

Menos de la mitad de las familias (41.4\%) recurre a la compra de garrafones de 20 litros a distribuidores locales para abastecerse de agua de consumo (Fig. 4b). Los restantes consumen agua provista por la red de los poblados (36.0\%), o la obtiene de fuentes secundarias como norias familiares o pequeños manantiales $(21.7 \%)$. El grado de adopción de prácticas de desinfección casera resultó asociado a la procedencia del agua de consumo, dado que las familias que no compran agua en garrafón muestran en general una mayor aplicación de desinfección casera. Existe, sin embargo, alrededor del $40 \%$ de familias que no acceden a agua comprada pero tampoco han adoptado dichas prácticas (Fig. 4b). 


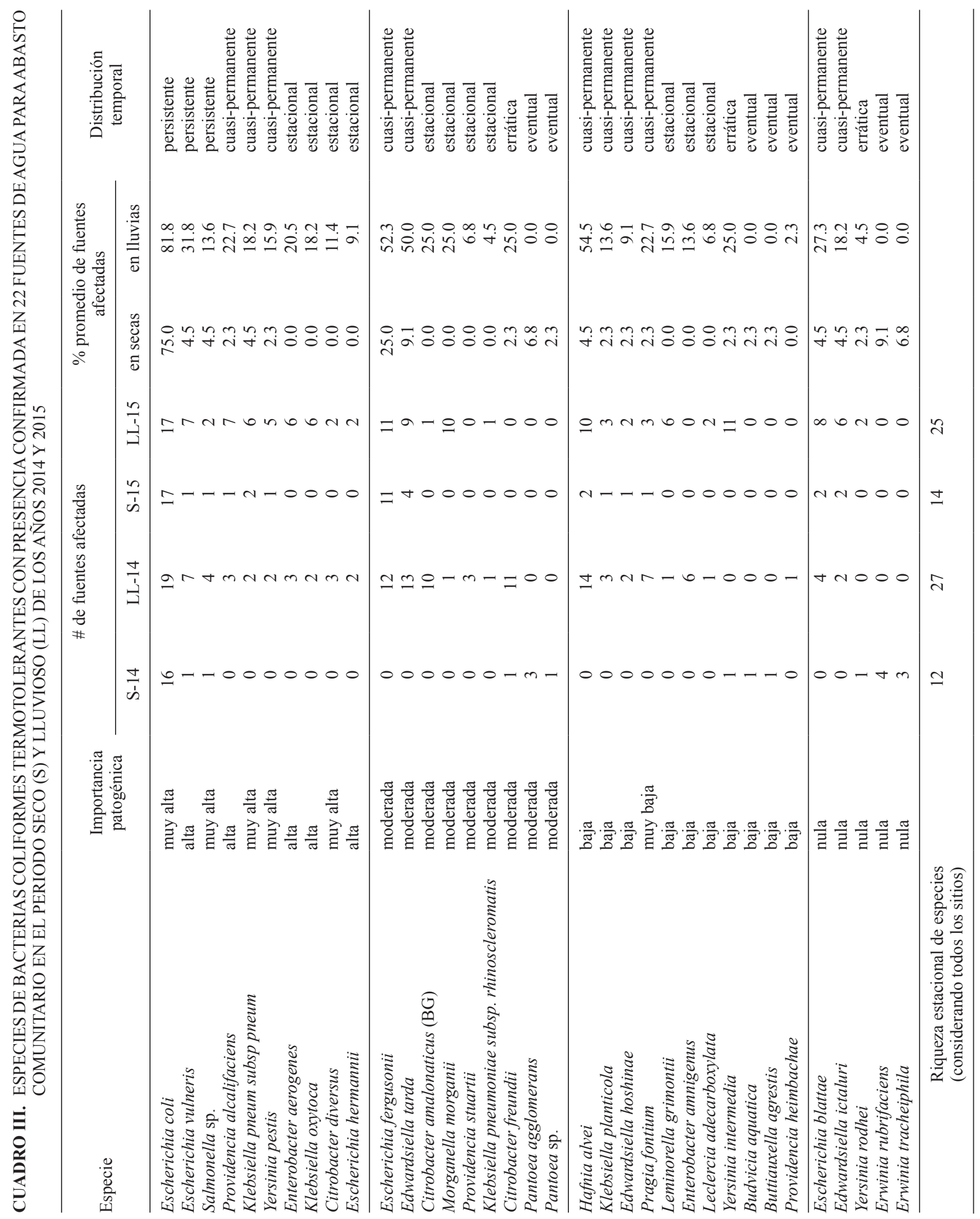


CUADRO IV. COMPARACIONES PAREADAS DE LA RIQUEZA DE ESPECIES DE BACTERIAS COLIFORMES TERMOTOLERANTES (CT) Y COLIFORMES DE ALTA IMPORTANCIA PATOGÉNICA (CAIP) PARA LOS SITIOS DE APROVECHAMIENTO DE AGUA $(\mathrm{n}=22)$ ENTRE EL PERIODO SECO (S) Y LLUVIOSO (LL) EN LOS AÑOS 2014 Y 2015

\begin{tabular}{llcc}
\hline \multirow{2}{*}{ Series pareadas } & \multicolumn{2}{c}{ Prueba de Wilcoxon } \\
\cline { 3 - 4 } & & \multicolumn{1}{c}{$\mathrm{Z}$} & $\mathrm{p}$ \\
\hline CT-S $_{14}$ & CT-LL $_{14}$ & 3.7626 & 0.0002 \\
CT-S $_{15}$ & CT-LL $_{15}$ & 3.5800 & 0.0003 \\
CT-S $_{14}$ & CT-S $_{15}$ & 0.7239 & 0.4691 \\
CT-LL $_{14}$ & CT-LL $_{15}$ & 0.5213 & 0.6021 \\
CAIP-S $_{14}$ & CAIP-LL $_{14}$ & 3.1243 & 0.0018 \\
CAIP-S $_{15}$ & CAIP-LL $_{15}$ & 3.7235 & 0.0002 \\
CAIP-S & CAIP-S $_{15}$ & 0.9335 & 0.3505 \\
CAIP-LL & CAIP-LL $_{15}$ & 1.5618 & 0.0002 \\
\hline
\end{tabular}

De las 203 familias encuestadas, 92casos (45.4\%) manifestaron que algún miembro de la familia padeció en el último año signos y síntomas atribuidos al consumo de agua de mala calidad, presumiblemente afectados por ETA. Sorpresivamente, la tabla de contingencia detectó una distribución equilibrada de casos entre las variables 'Desinfección casera' y 'Manifestación de ETA', con valores cercanos a los porcentajes de los totales marginales (Fig.4c). Este resultado puede interpretarse como independencia entre ambas variables. Sin embargo, los casos 'NoNo' capturaron principalmente al grupo de encuestados que son consumidores de agua en garrafones (31 sobre 54 casos). Los restantes 22 casos fueron familias que declararon no ser afectados por ETA, si bien consumen agua desde fuentes sin control microbiológico (red del poblado, fuentes secundarias), y sin desinfección casera. Los casos 'Si-Si' correspondieron principalmente a familias que consumen el agua directamente de fuentes no controladas y sí aplican procedimientos caseros de desinfección ( 35 sobre 44 casos), pero que igualmente han sufrido episodios de ETA. Ello sugiere deficiencias en el procedimiento casero de desinfección o contaminación cruzada al interior de la vivienda. Las ETA con menciones más frecuentes fueron diarreas acompañadas de dolor abdominal, fiebre o vómitos. Para la atención de estos cuadros clínicos las familias acudieron a las casas comunitarias de salud (63.7\%), pero un importante número recurrió a remedios caseros, o a la combinación de ambas formas de atención. Los servicios públicos de salud no ofrecieron un diagnóstico clínico en el $72 \%$ de las consultas realizadas. Los casos diagnosticados (26 de 92 afectados) reportaron gastroenteritis, fiebre tifoidea e infecciones estomacales y renales. Entre los encuestados surgió un amplio consenso $(61.3 \%)$ de que las ETA se manifiestan en el periodo lluvioso; sólo un $10.1 \%$ de encuestados las ubicó exclusivamente en el seco. Si bien el $52.7 \%$ de los encuestados señaló a la población infantil como la principal afectada, otro $29 \%$ indicó que toda la familia y los adultos en edad productiva son afectados por igual.

\section{DISCUSIÓN}

El sistema hidrográfico del Bajo Balsas (Michoacán) mostró una calidad microbiológica deficiente de las fuentes de agua que abastecen a las pequeñas localidades rurales, sin importar la ubicación por cuencas, altitud o sector hidrográfico (i.e. orden de corriente). La baja calidad microbiológica se manifestó en la presencia extendida en el espacio y en el tiempo de E. coli, con presencia más restringida de Salmonella sp. Otras especies típicas de contaminación del agua rural en países en desarrollo como Vibrio colera y los géneros Shigella y Campylobacter (Momba y Kaleni 2002) no fueron detectadas en este estudio. En cambio, se confirmó la presencia de otras bacterias con alta importancia patogénica como Escherichia vulneris relacionada con su alojamiento en heridas, urosepsis, bacteremia y encefalitis (Mohanty et al. 2005) y Providencia alcalifaciens asociada a diarreas en infantes (Albert et al. 1998). La detección de Klebsiella pneumoniae y Yersinia pestis, si bien con presencia menos extendida en el sistema hidrográfico, conlleva un alerta de atención pues ambas representan fuertes riesgos para la salud familiar. La primera está asociada con infecciones urinarias, neumonías, sepsis e infecciones de tejidos blandos (Babu et al. 2015) mientras que la segunda es el agente causante de pestes (Perry y Fetherston 1997). La cepa de Yersinia pestis es una patógena invasiva en humanos y está presente en animales silvestres, principalmente en roedores los cuales son el vector de contagio cuyo vehículo es la pulga. También existen otras vías de contagio como la inhalación de aerosoles (pequeñas gotas de líquido suspendidas en la atmósfera) y la contaminación directa de persona a persona (Rocha et al. 2004). Aunque de manera silvestre la bacteria no se puede reproducir en ambientes acuáticos (Ramírez et al. 2015), puede ser transportada por líquidos contaminados por secreciones de vertebrados o bien por fluidos de cadáveres (Inglesby et al. 2000, Riedel 2005). En las cuencas del Bajo Balsas la presencia de $Y$. pestis estaría explicada por el común hábito 

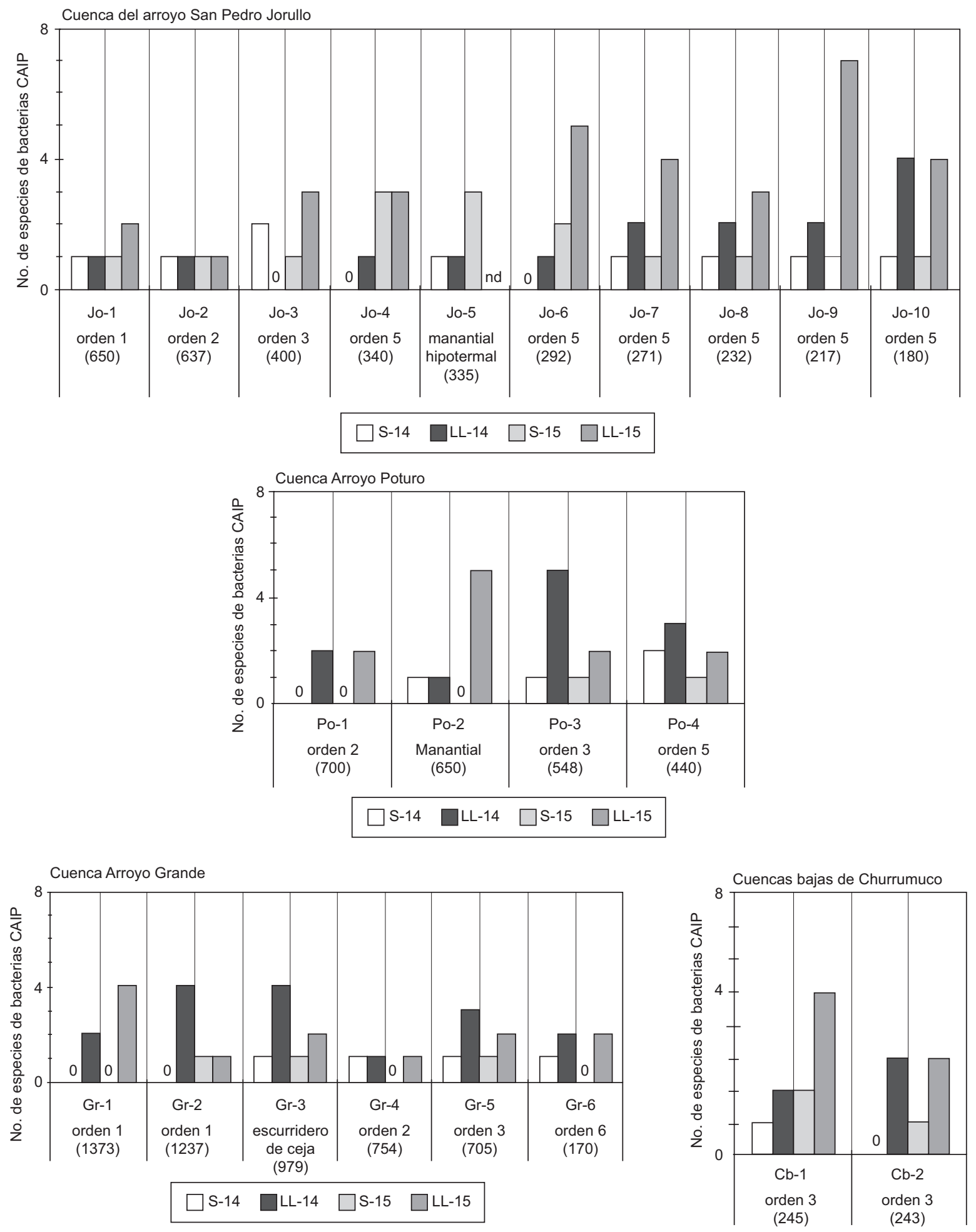

Fig. 3. Riqueza de especies de bacterias coliformes de alta importancia patogénica (CAIP) en sitios de aprovechamiento comunitario de agua (ver Cuadro I) en el periodo seco (S) y lluvioso (LL) de los años 2014 y 2015. En cada sitio se indica el orden de corriente de la línea de drenaje donde está ubicado y su altitud (en metros sobre el nivel del mar) 


\begin{tabular}{|c|c|c|c|}
\cline { 2 - 3 } \multicolumn{1}{c|}{$(\mathrm{a})$} & \multicolumn{2}{c|}{ Desinfección casera } & \multicolumn{1}{c}{} \\
\hline Recibió información & $\mathrm{Si}$ & No & Total \\
\hline \multirow{2}{*}{$\mathrm{Si}$} & 56 & 38 & 94 \\
& $(55.4 \%)$ & $(37.3 \%)$ & $(46.3 \%)$ \\
\hline \multirow{2}{*}{ No } & $\begin{array}{c}45 \\
(44.6 \%)\end{array}$ & $\begin{array}{c}64 \\
(62.7 \%)\end{array}$ & $\begin{array}{c}109 \\
(53.7 \%)\end{array}$ \\
\hline \multirow{2}{*}{} & 101 & 102 & 203 \\
\hline
\end{tabular}

\begin{tabular}{|c|c|c|c|}
\hline (b) & \multicolumn{2}{|c|}{ Desinfección casera } & \\
\hline $\begin{array}{l}\text { Procedencia del agua } \\
\text { de consumo }\end{array}$ & $\mathrm{Si}$ & No & Total \\
\hline $\begin{array}{l}\text { comprada en } \\
\text { garrafones de } 20 \mathrm{~L}\end{array}$ & $\begin{array}{c}22 \\
(21.8 \%)\end{array}$ & $\begin{array}{c}62 \\
(61.8 \%)\end{array}$ & $\begin{array}{c}84 \\
(41.3 \%)\end{array}$ \\
\hline $\begin{array}{l}\text { red de agua del } \\
\text { poblado }\end{array}$ & $\begin{array}{c}46 \\
(45.5 \%)\end{array}$ & $\begin{array}{c}27 \\
(26.5 \%)\end{array}$ & $\begin{array}{c}73 \\
(36.0 \%)\end{array}$ \\
\hline fuentes secundarias & $\begin{array}{c}33 \\
(32.7 \%)\end{array}$ & $\begin{array}{c}11 \\
(10.8 \%)\end{array}$ & $\begin{array}{c}44 \\
(21.7 \%)\end{array}$ \\
\hline $\begin{array}{l}\text { comprada y otra } \\
\text { fuente }\end{array}$ & $\begin{array}{c}0 \\
(0.0 \%)\end{array}$ & $\begin{array}{c}2 \\
(2.0 \%)\end{array}$ & $\begin{array}{c}2 \\
(1.0 \%)\end{array}$ \\
\hline & 101 & 102 & 203 \\
\hline
\end{tabular}

\begin{tabular}{|c|c|c|c|}
\hline (c) & \multicolumn{2}{|c|}{ Manifestación de ETA } & \\
\hline Desinfección casera & $\mathrm{Si}$ & No & Total \\
\hline $\mathrm{Si}$ & $\begin{array}{c}44 \\
(47.8 \%)\end{array}$ & $\begin{array}{c}57 \\
(51.4 \%)\end{array}$ & $\begin{array}{c}101 \\
(49.8 \%)\end{array}$ \\
\hline No & $\begin{array}{c}48 \\
(52.2 \%)\end{array}$ & $\begin{array}{c}54 \\
(48.6 \%)\end{array}$ & $\begin{array}{c}102 \\
(50.2 \%)\end{array}$ \\
\hline & 92 & 111 & 203 \\
\hline
\end{tabular}

Fig. 4. Tablas de contingencia para el análisis de encuestas familiares sobre manejo intradomiciliario del agua e incidencia de enfermedades transmitidas por el agua (ETA). $\mathrm{N}=203$, aplicadas en 18 localidades del área de estudio

rural de arrojar los cadáveres de animales muertos en barrancas y áreas ribereñas, con su descomposición al aire libre y el consecuente arrastre de fluidos a las fuentes de agua.

La severidad de la contaminación de las fuentes de agua mostró una clara incidencia de la estacionalidad climática. A finales del periodo lluvioso, la riqueza y la diseminación espacial de las especies coliformes fecales fue de mayor magnitud que a finales del seco. En el trópico seco, la dinámica estacional de la comunidad bacteriana puede analizarse a partir de la dinámica hidrológica del ecosistema completo (Maass y Burgos 2011). En la zona del Pacifico mexicano las lluvias inician a mediados del mes de junio y se detienen en la primera quincena de octubre, con cuatro a cinco meses de fuerte actividad hidrológica. A finales de octubre concluye definitivamente el arrastre de materiales por escurrimiento e infiltración. La condición microbiológica de las fuentes en octubre parece reflejar la comunidad bacteriana que alcanzó los mantos acuíferos y flujos subsuperficiales de agua y se estabilizó en esos ambientes durante el periodo lluvioso. A partir de octubre, las condiciones hidrológicas son menos dinámicas hasta alcanzar un mínimo en mayo. Estos cambios se reflejan en la senescencia completa de la vegetación nativa de la selva baja y en el acoplamiento de todos los procesos fisio ecológicos del ecosistema a la detención de los flujos hídricos (Ceballos et al. 2010). La ausencia de movimiento de agua conduce a una alta estabilidad en las fuentes de agua, con nula movilidad hidráulica y mayor concentración de sustancias en el agua por reducción de volúmenes por evapotranspiración. La disminución de la riqueza de especies detectada a finales de mayo parece indicar una alta mortalidad de bacterias durante el periodo seco, con efectos drásticos en aquellas especies que llegan a desaparecer en el mes de mayo. Durante los seis a siete meses de inactividad hidrológica los desechos fecales del ganado y la fauna silvestre se producen y acumulan principalmente en las áreas ribereñas de las líneas de drenaje donde persisten ojos de agua y pozas, sombra, alimento y refugios. En muchas comunidades, la falta de servicios sanitarios conlleva a la defecación al aire libre al amparo de las áreas ribereñas. Con el inicio de las lluvias, el material fecal es fácilmente arrastrado y lixiviado a los acuíferos aluviales y manantiales. Flores-López et al. (2012) mostraron que el estiércol de ganado vacuno es altamente contaminante con $E$. coli y generador de contaminación bacteriológica difusa, con mayores arrastres al inicio de las primeras lluvias estacionales. Dado que en el trópico seco la ganadería bovina extensiva es una actividad dominante, estos focos de contaminación no puntual parecen reproducirse en todos los sectores de las cuencas, independientemente del orden de corriente de las líneas de drenaje. Similares efectos espacialmente extendidos en las cuencas reportaron Torres et al. (2013) en Veracruz (México) bajo un clima más lluvioso y templado que en el trópico seco. Los arrastres bacterianos por efecto de las lluvias son un agente de contaminación no puntual debido a la recarga rápida que estos flujos producen en acuíferos, manantiales y cuerpos de agua superficiales (Pedley y Howard 1997, Crabill et al. 1999).

La severidad de la contaminación microbiológica encontrada en este estudio es una amenaza a la salud de las familias campesinas. En esta región 
las comunidades asumen que las fuentes de agua provenientes de partes altas, norias cerradas o garrafones adquiridos proveen agua segura. Por ello, las deficiencias detectadas en el manejo intradomiciliario del agua alertan sobre la necesidad de incrementar el acceso a la información para una mejor adopción de prácticas domésticas de desinfección del agua. La fuerte relación entre el acceso a la información y la adopción de estas técnicas es similar e numerosos estudios d países en desarrollo (Yassin et al. 2006). La cloración es la técnica más difundida, pero su buen uso y aplicación en la población rural marginada requiere supervisión regular (Wright et al. 2004). La severidad de la contaminación de las fuentes puede exacerbarse en el hogar debido a la concentración bacteriana en los contenedores domésticos (Momba y Notsche 2003, Günther y Schipper 2013). Las dificultades de la población vulnerable para acceder a los servicios de salud con diagnósticos certeros y medicinas alerta sobre la necesidad de mayores acciones de prevención que reduzcan las amenazas a la salud derivadas de la calidad deficiente de las fuentes de agua.

\section{CONCLUSIONES}

Las fuentes de abasto comunitario de agua en cuencas rurales estacionales del Bajo Balsas (Michoacán) presentaron contaminación por bacterias coliformes termoestables extendida en el tiempo, i.e. tanto en el periodo seco como el lluvioso y en el espacio, i.e. en sitios de aprovechamiento de todo el sistema hidrográfico. Se detectaron diez bacterias de alta importancia patogénica entre las que destacó $E$. coli por su amplia presencia espacio-temporal, y en menor grado Salmonella sp., E. vulneris, Providencia alcalifaciencis y Yersinia pestis. La severidad de la contaminación fue mayor en el periodo lluvioso, tanto por la riqueza de especies bacterianas como por la dispersión entre sitios. Ello está asociado al transporte y lixiviación de deshechos fecales de ganado, fauna silvestre y población humana, acumulados durante el periodo seco. En estas cuencas, aun los sitios alejados de poblados en partes altas de cerros y cejas de montaña, son susceptibles de contaminación. Esta condición representa una amenaza a la salud de las familias campesinas que puede ser reducida con una mayor diseminación de información oportuna, lo que incide claramente en la adopción de técnicas domesticas de desinfección. Ello es requerido para las familias sin acceso a compra de agua para consumo así como también para aquellas que sí lo hacen pero pueden estar incurriendo en contaminación cruzada al interior de la vivienda. La atención a la calidad microbiológica del agua y a los medios disponibles en la población para su propia protección sanitaria deben ser componentes básicos de las estrategias integrales para el alcance de la seguridad hídrica en cuencas rurales del trópico seco en México.

\section{REFERENCIAS}

Akoachere J-F.T.K., Omam L-A. y Massalla T.N. (2013). Assessment of the relationship between bacteriological quality of dug-wells, hygiene behaviour and well characteristics in two cholera endemic localities in Douala, Cameroon. BMC Public Health 13, 692.

DOI: $10.1186 / 1471-2458-13-692$

Albert J.M., Faruque A.S.G. y Mahalanabis D. (1998). Association of Providencia alcalifaciens with diarrhea in children. J. Clin. Microbiol. 36 (5), 1433-1435.

Amenu K., Spengler M., Markemann A. y Zárate A.V. (2014). Microbial quality of water in rural households of Ethiopia: implications for milk safety and public health. J. Health Popul. Nutr. 32 (2), 190-7.

Babu L., Murali H.S. y Batra V.H. (2015). Incidence of Klebsiella pneumoniae subsp pneumoniae in food and environmental samples isolated from Mysore City, India and its antibiogram. Int. J. Pharm. Biol. Sci. 6 (4), 635-641.

Bain R.E.S., Cronk R., Wright J., Yang H., Slaymaker T. y Bartram J. (2014a). Fecal contamination of drinking-water in low- and middle-income countries: A systematic review and meta-analysis. PLoS Med.11 (5), e1001644. DOI: 10.1371/journal.pmed.1001644

Bain R.E.S., Wright J.A., Christenson E. y Bartram J.K. (2014b). Rural: urban inequalities in post 2015 targets and indicators for drinking-water. Sci. Total. Environ. 490, 509-513. DOI: 10.1016/j.scitotenv.2014.05.007

Brooks G.F., Carroll K.C., Butel J.S., Morse S.A. y Mietzner T.A. (2011). Jawetz, Melnick y Adelberg Microbiología Médica. 25 Edición. McGraw Hill Interamericana, Ciudad de México, México, 815 pp.

Burgos A., Páez, R., Carmona E. y Rivas H. (2013). A systems approach to modeling community-based environmental monitoring: a case of participatory water quality monitoring in rural Mexico. Environ. Monit. Assess. 185 (12), 10297-10316. DOI: $10.1007 / \mathrm{s} 10661-013-3333-\mathrm{x}$

Ceballos G., Martínez L., García A., Espinoza E., Bezaur J.C. y Dirzo R. (Eds.). (2010). Las selvas secas del Pacífico Mexicano. Fondo de Cultura Económica. Comisión Nacional para el Conocimiento y Uso de la Biodiversidad. Ciudad de México, México, 594 pp. 
CONAPO (2012). Índice de marginación por localidad 2010. Capitulo 3. Consejo Nacional de Población. Ciudad de México, México, 36 pp.

Crabill C., Donald R., Snelling J., Foust R. y Southam G. (1999). The impact of sediment fecal coliform reservoirs on seasonal water quality in Oak Creek, Arizona. Wat. Res. 33 (9), 2163-2171.

DOI: 10.1016/S0043-1354(98)00437-0

Crumlish M., Dung T.T., Turnbull J.F., Ngoc N.T.N. y Ferguson H.W. (2002). Identification of Edwardsiella ictaluri from diseased freshwater catfish, Pangasius hypophthalmus (Sauvage), cultured in the Mekong Delta, Vietnam. J. Fish Dis. 25 (12), 733-736. DOI: 10.1046/j.1365-2761.2002.00412.x

Fewtrell L. y Bartram J. (2001). Water quality guidelines, standards and health: assessment of risk and risk management for water-related infectious disease. World Health Organization, Geneva, Suiza, 424 pp.

Flores López H.E., Hernández Jauregui A.L., Figueroa Viramontes U. y Castañeda Villanueva A.A. (2012). Calidad microbiológica del agua por contaminación difusa de la aplicación de estiércoles en maíz y pasto. Tecnol. Cienc. Agua III, 127-141

Fung D.Y.C. (2014). Biochemical and Modern Identification Techniques. En: Encyclopedia of food microbiology (C. A. Batt, Ed.). Elsevier. Amsterdam, Holanda, pp. 223-231.

Günther I. y Schipper Y. (2013). Pumps, germs and storage: the impact of improved water containers on water quality and health. Health Econ. 22 (7), 757-774. DOI: $10.1002 /$ hec. 2852

Holt J.G., Krieg N.R., Sneath P.H. A., Staley J.T. y Williams A.T. (1994). Bergey's manual of determinative bacteriology. 9th Ed. Williams and Wilkins. Baltimore, Maryland, EUA, 787 pp.

Inglesby T.V., Dennis D.T, Henderson D.A., Bartlett J.G., Ascher M.S., Eitzen E., Fine A.D., Friedlander A.M., Hauer J., Koerner J.F., Layton M., McDade J., Osterholm M.T., O’Toole T., Parker G., Perl T.M., Russell P.K., Schoch-Spana M. y Tonat K. (2000). Plague as a biological weapon: medical and public health management. JAMA. 283 (17), 2281-2290.

DOI: 10.1001/jama.283.17.2281

Jagals P., Barnard T.G., Mokoena M.M., Ashbolt N. y Roser D.J. (2013). Pathogenic Escherichia coli in rural household container waters. Water Sci. Technol. 67 (6), 1230-7. DOI: 10.2166/wst.2013.677

Maass M. y Burgos A. (2011). Water dynamics at the ecosystem level in seasonally dry tropical forests. En: Seasonally dry tropical forests (R. Dirzo, H. S. Young, H. A. Mooney y G. Ceballos, Eds.). Island Press/Center for Resource Economics, Washington, DC, EUA, pp. 141-156
Mohanty S., Chandra S. P., Dhawan B., Kapil A. y Das K.B. (2005). Meningitis due to Escherichia vulneris. Neurol. India 53 (1), 122-123.

DOI: $10.4103 / 0028-3886.15082$

Momba M.N. y Kaleni P. (2002). Regrowth and survival of indicator microorganisms on the surfaces of household containers used for the storage of drinking water in rural communities of South Africa. Water Res. 36 (12), 3023-3028. DOI: 10.1016/S0043-1354(02)00011-8

Momba M.N. y Notshe T.L. (2003). The microbiological quality of groundwater-derived drinking water after long storage in household containers in a rural community of South Africa. J. Water Supply Res. T. 52 (1), 67-77.

Mpenyana-Monyatsi L., Onyango M.S. y Momba M.N. (2012). Groundwater quality in a South African rural community: A possible threat to public health. Pol. J. Environ. Stud. 21 (5), 1349-1358.

Nogueira G., Nakamura C.V, Tognim M.C.B. y Filho B.A. (2003). Microbiological quality of drinking water of urban and rural communities, Brazil. Rev. Saúde Pública 37 (2), 232-236.

DOI: $10.1590 / \mathrm{S} 0034-89102003000200011$

OCDE (2015). Estudios económicos de la OCDE México. Organización para la Cooperación y el Desarrollo Económico, 44 pp. [en línea]. http://www.oecd.org/ economy/surveys/Mexico-Overview-2015\%20Spanish.pdf 20/03/2016

Pedley S. y Howard G. (1997). The public health implications of microbiological contamination of groundwater. Q. J. Eng. Geol. Hydroge. 30 (2), 179-188. DOI: 10.1144/GSL.QJEGH.1997.030.P2.10

Perry D.R. y Fetherston D.J. (1997). Yersinia pestisetiologic agent of plague..Clin. Microbiol. Rev. 10 (1), 35-66.

Ramírez C.L.M., Soto U.L., Baca B.E. y Martínez M.L. J. (2015). Evolución de Yersinia pseudotuberculosis. Elementos 97 (22), 29-33.

Riedel S. (2005). Plague: from natural disease to bioterrorism. Proc. Bayl. Univ. Med. Cent. 18 (2), 116-124.

Rocha G.R.C., Lozano Z.P. y Martínez L.Y. (2004). Mecanismos de patogenicidad e interacción parásitohospedero. Benemérita Universidad Autónoma de Puebla. Puebla, México, 329 pp.

Rosa G., Huaylinos M.L., Gil A., Lanata C. y Clasen T. (2014). Assessing the consistency and microbiological effectiveness of household water treatment practices by urban and rural populations claiming to treat their water at home: A case study in Peru. PLoS ONE 9 (12), e114997. DOI: 10.1371/journal.pone.0114997

Sandle T. (2014). Biochemical and modern identification techniques. En: Encyclopedia of food microbiology (C. A. Batt, Ed.). Elsevier. Amsterdam, Holanda, pp. 238-243. 
SCFI (2013). NMX-AA-042-2011 Análisis de aguadetección y enumeración de organismos coliformes, organismos coliformes termotolerantes y Escherichia coli presuntiva método del número más probable en tubos múltiples. Diario Oficial de la Federación. 13 de agosto de 2013.

SIODM (2015). Objetivos de desarrollo del milenio. Sistema de Consulta de los Indicadores de los Objetivos de Desarrollo del Milenio [en línea] http://www. objetivosdedesarrollodelmilenio.org.mx/ 23/03/2016

Torres B.B., González L.G., Rustrián P.E. y Houbron E. (2013). Enfoque de cuenca para la identificación de fuentes de contaminación y evaluación de la calidad de un río, Veracruz, México. Rev. Int. Contam. Ambie. 29 (3), 135-146.

Trejo I. (1999). El clima de la selva baja caducifolia en México. Investigaciones geográficas 39, 40-52.

Trevett A.F., Carter R. y Tyrrel S. (2004). Water quality deterioration: a study of household drinking water quality in rural Honduras. Int. J. Environ Heal. R. 14 (4), 273-283. DOI: 10.1080/09603120410001725612
Valenzuela M., Lagos B., Claret M., Mondaca M.A., Pérez C. y Pérez P.O. (2009). Fecal contamination of groundwater in asmall rural dryland watershed in Central Chile. Chilean J. Agric. Res. 69 (2), 235-243.

WHO (2011). Guidelines for drinking-water quality - Volume 1: Recommendations. World Health Organization. Geneva, Suiza, 668 pp.

Wright J., Gundry S. y Conroy R. (2004). Household drinking water in developing countries: a systematic review of microbiological contamination between source and point of use. Trop. Med. Int. Health 9 (1), 106-117. DOI: 10.1046/j.1365-3156.2003.01160.x

Yassin M.M., Amr S.S.A. y Al-Najar H.M. (2006). Assessment of microbiological water quality and its relation to human health in Gaza Governorate, Gaza Strip. Public Health 120 (12), 1177-1187.

DOI: 10.1016/j.puhe.2006.07.026 